\title{
O CONTROLE DE CONVENCIONALIDADE DIFUSO DE OFíCIO E A VEDAÇÃO DAS DECISÕES-SURPRESA
}

\section{THE CONVENTIONALITY CONTROL DIFFUSE EX OFFICIO AND THE PROHIBITION OF SURPRISE DECISIONS}

\author{
Matheus Lins Rocha ${ }^{1}$ \\ Olavo Augusto Vianna Alves Ferreira² \\ Maria Cristina Vidotte Blanco Tarrega ${ }^{3}$
}

\begin{abstract}
Resumo: $O$ controle de convencionalidade é um importante mecanismo utilizado com a finalidade de promover a adequação do ordenamento jurídico brasileiro infraconstitucional aos tratados internacionais de direitos humanos. Ainda pouco utilizado pelos juristas, o controle de convencionalidade em sua modalidade difusa é objeto de estudo no âmbito do processo civil brasileiro. O objetivo deste trabalho é a análise da realização do referido controle diante dos princípios do devido processo legal, do contraditório e da ampla defesa, bem como no que tange às regras e demais princípios elencados no Código de Processo Civil de 2015, dentre elas, sobretudo, a que prevê a vedação das "decisões surpresa" no âmbito processual, elencada no artigo 10 do referido diploma. O método empregado será o dedutivo e a técnica metodológica será a pesquisa teórica, partindo-se da análise das pesquisas bibliográficas, da legislação e da jurisprudência, para a aplicação das proposições e conclusões no caso concreto. Será possível verificar, como resultado, de que forma deve ser realizado o controle de convencionalidade difuso, respeitando-se as normativas processuais do Estado Democrático de Direito.
\end{abstract}

Palavras-chave: Controle de convencionalidade difuso. Vedação das decisões-surpresa. Direitos humanos fundamentais.

\begin{abstract}
The conventionality control is an important mechanism used to promote the adaptation of the infraconstitutional Brazilian legal order to international human rights treaties. Still little used by the legal operators, the conventionality control in its diffuse modality is object of study in the scope of the Brazilian civil process. The objective of this work is the analysis of the accomplishment of this control in the face of the principles of due process, contradictory and ample defense, as well as with regard to the rules and other principles listed in the Code of Civil Procedure of 2015, among them, above all, which provides for the prohibition of "surprise decisions" in the procedural scope, listed in Article 10 of the said diploma. The method used will be the deductive and the methodological technique will be the theoretical research, starting from the analysis of the bibliographical researches, the legislation and the jurisprudence, for the application of the propositions and conclusions in practice. It will be possible to verify, as a result, how the control of diffuse convention should be carried out, respecting the procedural norms of the Democratic State.
\end{abstract}

Keywords: Diffuse conventionality control. Prohibition of surprise decisions. Fundamental human rights.

Recebido em 27 de junho de 2018 Avaliado em 30 de julho de 2018 (AVALIADOR A) Avaliado em 17 de julho de 2018 (AVALIADOR B) Avaliado em 22 de julho de 2018 (AVALIADOR C) Aceito em 22 de novembro de 2018

\footnotetext{
Pós-graduado em Direito Público na Faculdade Baiana de Direito; Rua Frederico Simões, 98, Salas 705-706, Caminho das Árvores, 41820-774, Salvador, Bahia, Brasil; https://orcid.org/0000-0002-8682-0901; matheuslins@linselins.com.br

2 Doutor em Direito do Estado (Subárea Direito Constitucional) pela Pontifícia Universidade Católica de São Paulo; Professor no Programa de Doutorado e Mestrado em Direito da Universidade de Ribeirão Preto; https://orcid.org/0000-0003-10674335; olavoaferreira@hotmail.com

3 Doutora em Direito Empresarial pela Pontifícia Universidade Católica de São Paulo; Professora Titular na Universidade Federal de Goiás e no Programa de Mestrado da Universidade de Ribeirão Preto; https://orcid.org/0000-0002-4805-4345; mcvidotte@uol.com.br
} 


\section{Introdução}

O controle de convencionalidade é um importante mecanismo na concreção dos direitos humanos e no diálogo transnacional nessa matéria, porque dá efetividade às normas internacionalmente convencionadas sobre o tema ao impulsionar os Estados ao seu cumprimento.

Enquanto o julgamento da Corte Interamericana de Direitos Humanos no caso Gomes Lund vs. Brasil evidencia que o Poder Judiciário brasileiro já se manteve omisso com relação à realização do controle de convencionalidade (I/A COURT H.R., 2010b), verifica-se que o referido controle já se mostrou bastante eficaz na efetivação dos direitos humanos fundamentais no âmbito da sua aplicação em estados latino-americanos, como, por exemplo, no julgamento dos casos denominados de Recurso de Hecho Gramajo, Marcelo do ano de 2006 e Mazzeo, Lulio Lilo y otros s/Recurso de Casación e Inconstitucionalidad de 13 de julho de 2007, pela Suprema Corte da Nação Argentina, bem como na Sentença do Tribunal Constitucional do Perú, que estabelece que os direitos fundamentais previstos internamente devem ser interpretados em conformidade com os tratados internacionais de direitos humanos (TRIBUNAL CONSTITUCIONAL DO ESTADO DO PERU, 2007).

No Brasil, a promulgação do Código de Processo Civil de 2015 trouxe a urgência do estudo do controle de convencionalidade à luz das regras e princípios estabelecidos na Constituição Federal informadores do referido diploma legal. Neste sentido, o mecanismo de controle é aqui discutido buscando-se a sua mais adequada ocorrência no ordenamento jurídico brasileiro. Para tanto, os princípios e regras constitucionais mais relevantes para o caso são abordados, sendo proposta a realização do referido controle pelo poder judiciário, de forma a respeitar às normativas processuais elencadas.

Neste contexto, primeiramente, traz-se um conceito do controle de convencionalidade com ênfase em sua importância para a efetivação dos direitos humanos fundamentais. Posteriormente, verifica-se a necessidade de promoção do controle de convencionalidade na sua modalidade difusa, bem como a sua realização de ofício pelo poder judiciário.

Diante disso, para constatar uma possível escorreita efetivação do controle de convencionalidade difuso, são discutidas as normativas processuais do Código de Processo Civil de 2015, notadamente no que se refere à vedação das denominadas "decisões surpresa" no processo civil brasileiro, com a finalidade de que o controle de convencionalidade seja realizado nos parâmetros constitucionais e adequado ao direito processual civil.

A presente pesquisa se justifica sobremaneira por sua relevância teórica e prática, uma vez que o controle de convencionalidade é ainda pouco conhecido e discutido na esfera do direito e pouco praticado no âmbito jurisdicional pátrio. Há, ademais, uma contradição insolúvel entre os posicionamentos do Supremo Tribunal Federal e de grande parte da doutrina, no que se refere à parametricidade do controle de convencionalidade, o que afeta, diretamente, o modo de ocorrência. Justifica-se, ainda, numa perspectiva de relevância teórica, pelo fato de que o discutido controle deve 
ser realizado na conformidade das normativas constitucionais processuais, para que não resulte em nulidade de decisões judiciais.

A relevância social da presente pesquisa também a justifica, tendo-se em vista o fato de a correta realização do controle de convencionalidade difuso no âmbito do processo civil brasileiro acarreta efetividade aos direitos humanos fundamentais dos indivíduos, por meio da jurisdição estatal, o que confere eficácia às próprias normas constitucionais.

Trata-se de uma pesquisa transdisciplinar no campo do direito, cruzando temáticas referentes às disciplinas do direito constitucional, do direito internacional, dos direitos humanos, bem como de direito processual civil. Na construção das assertivas, é utilizado o método dedutivo de raciocínio, partindo-se da análise de regras gerais propostas na Constituição Federal, bem como no Código de Processo Civil, para o caso específico da realização do controle de convencionalidade difuso, de ofício, observando-se o devido processo legal, bem como as demais normas constitucionais

processuais. A vertente metodológica do presente trabalho corresponde à jurídico-dogmática, tendo em vista que este se limita à análise do ordenamento jurídico brasileiro, especificamente no que se refere às regras e princípios ali declinados, sem se considerar a interferência dos outros segmentos do conhecimento humano.

A linha deste trabalho é a crítico-metodológica, uma vez que objetiva repensar o direito realizando-se o controle de convencionalidade difuso, de acordo com as normativas do direito processual civil. Esta pesquisa trabalhou com dados primários, colhidos da legislação, e da jurisprudência, bem como utilizou-se reflexões teóricas dos juristas. Trata-se de pesquisa teórica, vislumbrando a construção de conceitos específicos e a análise de diferentes argumentações aportadas pelos estudiosos dos referidos ramos do direito, para a elaborar conclusões e proposições.

\section{Controle de Convencionalidade como efetivador dos direitos humanos fundamentais}

Diante do quadro de fortalecimento dos direitos humanos, sobretudo pela busca de sua concretização pelo Poder Judiciário, o mecanismo do controle de convencionalidade serve como importante instrumento para que os ordenamentos jurídicos dos Estados possam, em conjunto, atingir esse objetivo.

O controle de convencionalidade pode ser conceituado como a "compatibilização das normas de direito interno com os tratados de direitos humanos ratificados pelo governo e em vigor no país." (MAZZUOLI, 2013, p. 79). Esta modalidade de controle foi citada, pela primeira vez, em 1975, pelo Conselho Constitucional Francês, constituindo um mecanismo de fundamental importância, utilizado para verificar se as normas de determinado ordenamento jurídico, ou atos praticados pelo Poder Público, são compatíveis com o disposto nos Tratados internacionais de direitos humanos ratificados pelo Estado respectivo. No âmbito da Corte Interamericana de Direitos Humanos, o Juiz 
Sérgio García Ramirez se referiu à expressão "controle de convencionalidade", pela primeira vez, no julgamento do Caso Myrna Mack Chang v. Guatemala, no item 27 de seu voto individual (I/A COURT H.R., 2003).

A doutrina estabelece que existem três vertentes de direitos fundamentais na Constituição Federal de 1988. Estas vertentes são fontes constitucionais de proteção dos direitos humanos e são comumente delimitadas em direitos expressos na Constituição, direitos previstos na Constituição de forma implícita, bem como os direitos expressos decorrentes de tratados internacionais que versam sobre direitos humanos em que o Estado brasileiro seja parte (MAZZUOLI, 2013, p. 137), sendo esta abrangência, fruto da cláusula aberta de não tipicidade dos direitos fundamentais (CUNHA JÚNIOR, 2015).

Neste sentido, o $\mathbb{2 ^ { \circ }}$ do artigo $5^{\circ}$ da Constituição Federal é cristalino ao afirmar que os direitos e garantias expressos na Constituição não excluem os demais, decorrentes dos tratados internacionais em que a República Federativa do Brasil seja parte. $\bigcirc \lessgtr 3^{\circ}$ do referido artigo, por sua vez, dispõe que "Os tratados e convenções internacionais sobre direitos humanos que forem aprovados, em cada Casa do Congresso Nacional, em dois turnos, por três quintos dos votos dos respectivos membros, serão equivalentes às emendas constitucionais." (BRASIL, 1988). Portanto, vislumbra-se que os tratados internacionais de direitos humanos possuem papel fundamental no ordenamento jurídico brasileiro, uma vez que a Constituição Federal afirma, a importância destes para a promoção dos direitos fundamentais.

Trindade (1991, p. 14-15) já falava, desde o século passado, da possibilidade de determinado Estado promover a adequação das leis internas às obrigações convencionais. Guerra (2013, p. 179) conceitua o mecanismo em questão como "um novo dispositivo jurídico fiscalizador das leis infraconstitucionais", enfatizado que as normas internas devem estar compatíveis com os tratados internacionais ratificados pelo país em questão, o que permite a eficácia das legislações internacionais, devendo ser aplicado pela Corte Interamericana ou pelos Tribunais dos países que ratificaram a Convenção. Ademais, o referido controle pode ser conceituado como "aquele exercido para verificar a compatibilidade das regras locais (direito interno) às convenções internacionais." (FIGUEIREDO, 2016, p. 87).

Vislumbra-se, portanto, que sendo incorporados determinados direitos humanos ao ordenamento jurídico brasileiro, pelos tratados internacionais referidos, o parâmetro dos mecanismos de controle do referido ordenamento se amplia. Assim, o controle de convencionalidade se apresenta como importante ferramenta para a efetivação dos direitos humanos fundamentais no Brasil. Já muito discutido e utilizado pelos tribunais da maioria dos países latino-americanos, o mecanismo atua como protetor das minorias e dos direitos fundamentais por meio da jurisdição constitucional (ABBOUD, 2017, p. 1). 
No que se refere ao direito português, Canotilho (2003, p. 824-825) afirma que as normas de determinado direito comunitário constituem o direito aplicável, de forma direta, no âmbito de todos os Estados que são membros, possuindo validade e eficácia imediata. Neste sentido, os referidos atos normativos atuam de forma a derrogar as leis internas portuguesas que dispuserem de forma conflitante. A primazia do direito comunitário, segundo o autor, é uma fonte normativa da própria ordem jurídico-constitucional.

Não se pode negar o fato de que o Poder Judiciário brasileiro já se manteve omisso com relação à realização do controle de convencionalidade conforme evidencia a Corte Interamericana de Direitos Humanos no julgamento do caso Gomes Lund vs. Brasil (I/A COURT H.R., 2010b). Entretanto, o controle de convencionalidade é fundamental para a efetivação dos direitos humanos fundamentais, notadamente no que diz respeito aos direitos coletivos garantidos pelas convenções internacionais das quais o Brasil é signatário. A realização do mecanismo de controle em estudo tem crescido gradativamente no âmbito dos países latino-americanos, bem como em esfera internacional pela Corte Interamericana de Direitos, por meio de sua jurisprudência, tendo como parâmetro, por exemplo, a Convenção Interamericana de Direitos Humanos, Convenção 169 da OIT, Convenção de Diversidade Biológica entre tantas outras.

Diante disso, conclui-se, inicialmente, que o parâmetro do mecanismo de controle é a grande diferença entre o controle de convencionalidade e o de constitucionalidade. Enquanto o controle de constitucionalidade objetiva a adequação das normativas infraconstitucionais à Constituição Federal, o controle de convencionalidade tem a finalidade de adequar as normas legais e os atos administrativos aos tratados internacionais de direitos humanos ratificados e em vigor no Brasil. Saliente-se que no momento em que determinado tratado internacional cria, reafirma ou reforça algum direito humano, poderá ser utilizado como parâmetro de controle de convencionalidade.

Diversos são os casos que evidenciam a consolidação do mecanismo de controle na jurisprudência da Corte Interamericana de Direitos Humanos. Merecem destaque os casos Myrna Mack Chang v. Guatemala, Almonacid Arellano e outros Vs. Chile, Trabalhadores Demitidos do Congresso Vs. Peru, Cabrera-García and Montiel-Flores Vs. Mexico, Gelman vs. Uruguay e Gomes Lund ("Guerrilha do Araguaia") vs. Brazil, todos disponíveis no site da Corte Interamericana de Direitos Humanos (http://www.corteidh.or.cr/, 16 de julho de 2017).

No que se refere a esse controle nos países latino-americanos, diversos estudos já evidenciam que o Chile (ALCALÁ, 2013), a Argentina (PIZZOLO, 2013; SAGÜÉS, 2013), o México (MACGREGOR, 2013), o Peru (BELAUNDE; MANCHEGO, 2013), o Uruguai (GALLICCHIO, 2013), a Costa Rica (ALCALÁ, 2013), a Colômbia (ALCALÁ, 2013) e a República Dominicana (ALCALÁ, 2013) se utilizam do controle de convencionalidade como importante meio para efetivação dos direitos humanos fundamentais, tendo sido a necessidade da utilização do referido controle proferida, de forma expressa, pelas respectivas cortes de cada Estado. 
Neste sentido, é possível citar alguns casos de aplicação do controle de convencionalidade no âmbito do direito interno de determinados Estados partes da Convenção Americana de Direitos Humanos. No que se refere ao direito chileno, vislumbra-se que, a partir da sentença Rol 1361-09, o Tribunal Constitucional do Chile passou a utilizar a regra básica de hermenêutica da utilização da norma mais benéfica, com base no princípio pro homine, assumindo, a Corte, que deve ser aplicada a norma que protege da melhor forma os direitos humanos (TRIBUNAL CONSTITUCIONAL CHILENO, 2009).

Com relação ao direito argentino, verifica-se, no caso denominado de Recurso de Hecho Gramajo, Marcelo do ano de 2006 em que a Suprema Corte declarou a incompatibilidade da pena de reclusão por tempo indeterminado prevista no artigo 52 do Código Penal Portenho, por violar os instrumentos internacionais sobre direitos humanos que, inclusive, fazem parte do bloco de constitucionalidade, de forma expressa, conforme disposto no artigo 75, inc. 22 da Lei Fundamental Argentina. Estabelece, ademais, a Suprema Corte da Argentina, no caso Mazzeo, Lulio Lilo y otros s/Recurso de Casación e Inconstitucionalidad de 13 de julho de 2007 que "el Poder Judicial debe ejercer una especie de 'control de convencionalidad' entre las normas jurídicas internas que aplican en los casos concretos y la Convención Americana sobre Derechos Humanos." (CORTE SUPREMA DE LA NACIÓN ARGENTINA, 2007).

O entendimento da Suprema Corte de Justicia de la Nación de México demonstrado na sessão pública datada de 12 de julho de 2011, é no sentido da obrigatoriedade da aplicação do Controle de Convencionalidade pelos Tribunais do Estado Mexicano, estabelecendo que "Es mayoría de siete votos en el sentido de que todos los tribunales del Estado Mexicano deben ejercer el control de convencionalidad." (SUPREMA CORTE DE JUSTICIA DE LA NACIÓN DE MÉXICO, 2011).

O Tribunal Constitucional do Estado do Peru, por meio da Sentença do processo EXP. n. 01458-2007-PA/TC estabeleceu que "Los derechos fundamentales reconocidos por nuestra Constitución, deben ser obligatoriamente interpretados de conformidad con los tratados y los convenios internacionales sobre derechos humanos ratificados por el Perú." (TRIBUNAL CONSTITUCIONAL DO ESTADO DO PERU, 2007). Ademais, no caso EXP. n. 01458-2007-PA/TC, o mesmo Tribunal estabelece no item 9, que as Leis incompatíveis com os tratados internacionais de direitos humanos ratificados pelo Peru devem ser declaradas nulas, por meio de um controle judicial, sendo relembrado, pelo julgado, a incompatibilidade das "Leyes de Amnistía n.os 26479 y 26492", declarada pela Corte Interamericana no caso Barrios Altos vs. Peru de 18 de septiembre de 2003.

Por fim, cabe lembrar que o Uruguai, por meio de sua Suprema Corte e a Bolívia, por meio de seu Tribunal Constitucional, já estabeleceram, em suas decisões na Sentença n. 365/2009 e 2006-13381-27-RAC, respectivamente, que a Convenção Americana de Direitos Humanos integra o bloco de constitucionalidade, sendo, portanto, parâmetro de controle do ordenamento jurídico interno infraconstitucional. A Suprema Corte de Justiça da República Dominicana, por sua vez, já 
estabeleceu, na resolução n. 1920-2003, o caráter vinculante das normas da Convenção Americana, bem como da interpretação oferecida pela Corte Interamericana.

O fato é que diversos avanços em sede de promoção e efetivação dos direitos humanos fundamentais já foram alcançados por meio da utilização do mecanismo de controle devendo este ser, cada vez mais, discutido e utilizado pelos operadores do direito brasileiro no que se refere ao respectivo ordenamento jurídico. A partir do controle de convencionalidade, as legislações brasileiras, bem como os atos administrativos estatais não poderão contrariar quaisquer disposições dos tratados internacionais de direitos humanos, sob pena de nulidade. Neste sentido, os direitos humanos fundamentais ganham uma nova ferramenta, apta para efetivá-los, uma vez que as convenções internacionais de direitos humanos deverão ser cumpridas nos âmbitos do legislativo, do executivo e do judiciário e ter seus preceitos respeitados também na ordem privada, pelo fato de integrarem o ordenamento jurídico nacional.

Com relação à parametricidade de controle no que tange ao ordenamento jurídico brasileiro, quatro teorias procuram definir a verdadeira posição hierárquico-normativa que detém os tratados internacionais de direitos humanos no ordenamento jurídico brasileiro:

a) $O$ antigo posicionamento do Supremo Tribunal Federal, que admitia os tratados internacionais de direitos humanos com status normativo de lei ordinária, não possui mais grande relevância no que se refere às discussões sobre o tema, diante das modificações implementadas. Verifica-se o referido posicionamento no julgamento da $\mathrm{ADI} 1480 \mathrm{MC} / \mathrm{DF}$ em que o Ministro relator Celso de Albuquerque Mello proferiu seu entendimento no sentido de que "Os tratados ou convenções internacionais, [...] situam-se, no sistema jurídico brasileiro, nos mesmos planos de validade, de eficácia e de autoridade em que se posicionam as leis ordinárias." (MELLO, 1997).

b) O entendimento do professor de direito internacional Mello (2001, p. 29), no sentido da supraconstitucionalidade dos tratados internacionais de direitos humanos, também não ganhou muitos adeptos, em que pese objetive a máxima promoção dos direitos humanos fundamentais, justamente pelo caráter da supremacia constitucional do ordenamento jurídico brasileiro.

c) A teoria mais utilizada pela doutrina de direitos humanos, com expoentes como Mazzuoli (2013, p. 62), Piovesan (1996, p. 83) e Trindade (1991, p. 89), é a que mais se adequa à maior efetividade ao mecanismo do controle de convencionalidade.

d) A referida teoria se utiliza do artigo $5^{\circ}, \mathbb{} 2^{\circ}$ da Constituição Federal, como cláusula constitucional aberta, para atribuir um status constitucional aos tratados internacionais de direitos humanos independentemente da forma de sua incorporação ao ordenamento 
jurídico brasileiro, ou seja, de forma independente do que dispõe o $₫ 3^{\circ}$ do referido artigo. Tal tese é corroborada pela previsão do artigo 4 ${ }^{\circ}$ II da Constituição Federal.

e) Para Mazzuoli (2013, p. 62), por exemplo, a formalidade da incorporação de determinado tratado internacional de direitos humanos ao ordenamento jurídico brasileiro somente definirá se o referido tratado possui status materialmente constitucional ou status material e formalmente constitucional. No primeiro caso, estariam as normas não incorporadas pelo $\int 3^{\circ}$ do artigo $5^{\circ}$ da Constituição, enquanto no segundo caso estariam as normas incorporadas nestes ditames. A relevância prática para esta diferenciação, ainda segundo o autor, seria que no primeiro caso, as normas poderiam ser parâmetro somente do controle de convencionalidade na sua modalidade difusa, enquanto no segundo caso as normas serviriam de parâmetro para o controle de convencionalidade, tanto na modalidade difusa, quanto na concentrada.

f) d) $O$ entendimento que prevalece no Supremo Tribunal Federal é o defendido pelo Ministro Gilmar Mendes no julgamento do Recurso Extraordinário 466.343-SP pelo Supremo Tribunal Federal. Foi definida a hierarquia supralegal e infraconstitucional aos tratados internacionais que versam sobre direitos humanos. Saliente-se que este voto foi o vencedor em um total de cinco contra quatro votos favoráveis ao entendimento do Ministro Celso de Mello que modificou seu entendimento, de forma radical, ao propor que se considerassem os tratados internacionais de direitos humanos como detentores de um status constitucional no ordenamento jurídico brasileiro.

Portanto, para o Supremo Tribunal Federal, os tratados internacionais, ratificados pelo Brasil, que versam sobre direitos humanos, sendo estes anteriores ou posteriores à Emenda Constitucional 45/2004, possuem status de norma infraconstitucional e supralegal, quando não tenham sido incorporados nos ditames do $₫ 3^{\circ}$ do artigo $5^{\circ}$ da Constituição Federal. Neste sentido, para o Supremo, somente serão equivalentes às Emendas Constitucionais e obterão status constitucional os Tratados Internacionais de Direitos Humanos que tenham sido incorporados conforme o disposto no referido $₫ 3^{\circ}$.

O fato é que, independentemente da teoria utilizada no que se refere à hierarquia dos tratados internacionais que versam sobre direitos humanos, o controle de convencionalidade já pode ser utilizado no ordenamento jurídico brasileiro, conforme voto do Ministro Teori Zavascki (SUPREMO TRIBUNAL FEDERAL, 2015), relacionado ao tema das audiências de custódia, que salientou que mesmo considerando a hierarquia dos tratados definida pelo Supremo, o controle deve ser exercido, aferindo-se a compatibilidade entre a norma legal e a supralegal.

Portanto, é possível vislumbrar, no âmbito do ordenamento jurídico brasileiro, a partir do julgamento do Recurso Extraordinário 466.343-SP pelo Supremo Tribunal Federal, que é possível controlar a convencionalidade das leis tendo como parâmetro os tratados internacionais de direitos 
humanos aprovados, pelo Congresso Nacional conforme o procedimento previsto no artigo $5^{\circ}$, $\mathbb{\int} 3^{\circ}$ da Constituição Federal. Temos, diante disso, como parâmetro de controle de convencionalidade a Convenção Internacional sobre os Direitos das Pessoas com Deficiência e seu Protocolo Facultativo, assinados em Nova York, na data 30 de março de 2007, aprovados pelo Congresso Nacional pelo Decreto Legislativo n. 186, de 9 de julho de 2008 e promulgados pelo Presidente da República pelo Decreto n. 6.949, de 25 de agosto de 2009. Saliente-se que o Tratado de Marraqueche para Facilitar o Acesso a Obras Publicadas às Pessoas Cegas, com Deficiência Visual ou com outras Dificuldades para Ter Acesso ao Texto Impresso, celebrado na data de 28 de junho de 2013, foi aprovado no mesmo procedimento, por meio do Decreto Legislativo n. 261, de 2015, dependendo, apenas, do Decreto Presidencial que o promulgue, para ingressar no ordenamento jurídico pátrio e ampliar a parametricidade do controle de convencionalidade.

Ademais, podemos extrair, ainda, do julgamento do Recurso Extraordinário 466.343SP pelo Supremo Tribunal Federal, a possibilidade de realização do controle de supralegalidade no ordenamento jurídico brasileiro, tendo como parâmetro os tratados internacionais de direitos humanos que não foram incorporados de acordo com o $\int 3^{\circ}$ do artigo $5^{\circ}$ da Constituição Federal, sendo possível vislumbrar uma parametricidade muito mais ampla e substancial.

Além do já mencionado voto do Ministro Teori Zavascki na Ação Direta de Inconstitucionalidade 5.240, de 20 de agosto de 2015, é possível verificar o exercício do controle de convencionalidade pelo Supremo Tribunal Federal no próprio Recurso Extraordinário 466.343SP, onde o Ministro Gilmar Mendes realiza o controle de supralegalidade do artigo 652 do Código Civil, que possibilitava a prisão do depositário infiel, estabelecendo, em seu voto, que "tendo em vista o caráter supralegal desses diplomas normativos internacionais, a legislação infraconstitucional posterior que com eles seja conflitante também tem sua eficácia paralisada. É o que ocorre, por exemplo, com o art. 652 do Novo Código Civil." (SUPREMO TRIBUNAL FEDERAL, 2008).

Nesse sentido, o Tribunal Superior do Trabalho, ao julgar o Recurso de Revista RR-107272.2011.5.02.0384 na data de 24 de setembro de 2014, aplicou o controle de supralegalidade, em sua

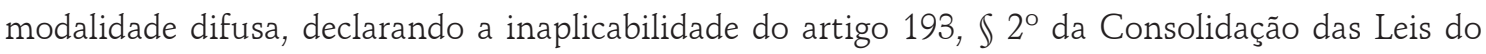
Trabalho, que afirma que o empregado "poderá optar pelo adicional de insalubridade que porventura lhe seja devido", por violar as Convenções 148 e 155 da Organização Internacional do Trabalho. O Ministro Cláudio Mascarenhas Brandão estabeleceu que "outro fator que sustenta a inaplicabilidade do preceito celetista é a introdução no sistema jurídico interno das Convenções Internacionais nos 148 e 155, com status de norma materialmente constitucional ou, pelo menos, supralegal, como decidido pelo STF." (TRIBUNAL SUPERIOR DO TRABALHO, 2014).

Vislumbra-se, portanto, que o mecanismo do controle de convencionalidade deve ser aplicado com o objetivo de concretizar a terceira vertente de direitos fundamentais explanada alhures, ou seja, os direitos expressos decorrentes dos tratados internacionais de direitos humanos em que o Estado brasileiro é signatário. 
No âmbito do ordenamento jurídico brasileiro, é cediço que existem duas formas de controle de constitucionalidade, sendo estas, o modelo concentrado, bem como o modelo difuso. Portanto, o Poder Judiciário deve exercer o controle concentrado da convencionalidade das leis e atos normativos por meio do Supremo Tribunal Federal, bem como o controle difuso de convencionalidade e de supralegalidade, pelo próprio Supremo ou por qualquer Juízo singular ou Tribunal. Neste sentido, para o presente estudo, deve-se elucidar o conceito e a forma de realização do controle de convencionalidade difuso, bem como a necessidade de ser realizada de ofício.

\section{Controle de Convencionalidade de ofício no controle difuso}

Cunha Júnior (2015 p. 119) afirma que o Controle de Constitucionalidade, em sua modalidade difusa, "é realizado no curso de uma demanda judicial concreta, e como incidente dela, por qualquer juiz ou tribunal." Da mesma forma, deve ser conceituado o controle de convencionalidade difuso como o controle das leis e atos normativos do ordenamento jurídico brasileiro, no âmbito incidental de uma demanda judicial, por qualquer Juiz ou Tribunal, tendo como parâmetro, os tratados internacionais de direitos humanos ratificados no Brasil e produzindo, tal decisão, efeitos inter partes.

Neste sentido, explicita Mazzuoli (2015, p. 252) que o controle difuso de convencionalidade "é aquele a ser exercido por todos os juízes e tribunais do País, a requerimento das partes ou ex officio." O controle de convencionalidade, em sua modalidade difusa, surge no ordenamento jurídico brasileiro, ainda segundo o autor, a partir da Constituição Federal de 1988. É verdade que, a partir de uma análise acurada do texto constitucional, verifica-se o artigo $5^{\circ}$, inciso III, alínea "a" já estabelecia, desde o ano de 1988 que o Poder Judiciário cumula a competência para proceder com o controle das decisões judiciais, desde à época, quando estas fossem incompatíveis com o estabelecido nos tratados internacionais de direitos humanos.

Mac-Gregor (2013, p. 549) enfatiza a importância da realização do controle difuso de convencionalidade pelos juízes e tribunais afirmando que "El control difuso de convencionalidad consiste em el deber de los juices nacionales em realizar um examen de compatibilidade entre los actos y normas nacionales, y la CADH, sus protocolos adicionales, y la jurisprudencia de la Corte IDH [...]"

No que se refere à parametricidade do controle de convencionalidade em sua modalidade difusa, diferentes doutrinadores divergem em seus respectivos posicionamentos.

Mazzuoli (2013, p. 108), em sua teoria acerca do controle de convencionalidade, entende que para que determinado tratado internacional de direitos humanos seja parâmetro do controle de convencionalidade concentrado, deve, obrigatoriamente, ter sido incorporado, pelo ordenamento jurídico brasileiro, nos ditames do $\int 3^{\circ}$ do artigo $5^{\circ}$ da Constituição Federal, tratado este que ostenta status material e formal constitucional. Entretanto, para que o referido tratado seja parâmetro para eventual controle de convencionalidade em sua modalidade difusa, basta que o diploma internacional 
seja incorporado pelo ordenamento jurídico, mesmo que este não tenha sido incorporado pelo referido quórum qualificado, ostentando, deste modo, para o autor, o status materialmente constitucional.

Todavia, Cunha Júnior (2016) entende que para que seja realizado o controle difuso de convencionalidade faz-se necessário que haja, também, um fundamento formal. Desta forma, segundo o autor, o controle de convencionalidade somente pode ter como sua parametricidade os tratados internacionais de direitos humanos que ostentem um caráter formalmente constitucional. O exemplo que torna o mecanismo já "palpável" no ordenamento jurídico brasileiro é, justamente, a Convenção Internacional sobre os Direitos das Pessoas com Deficiência, bem como seu Protocolo Facultativo, assinados em Nova York, na data de 30 de março de 2007, sendo promulgado pelo Decreto n. 6.949, de 25 de agosto de 2009.

O Supremo Tribunal Federal, como já discutido, proferiu seu entendimento no sentido de que os tratados internacionais que versam sobre direitos humanos não incorporados pelo quórum qualificado do artigo $5^{\circ}, \mathbb{S} 3^{\circ}$ da Constituição Federal ostentam status de norma supralegal e infraconstitucional, devendo ser, portanto, realizado um verdadeiro controle de supralegalidade como no caso da proibição da prisão do depositário infiel pela Convenção Americana de Direitos Humanos.

A jurisprudência da Corte Interamericana de Direitos Humanos já se consolidou no sentido de que os Estados devem proceder com o controle de convencionalidade em sua modalidade difusa, sendo dever dos Juízes e Tribunais a realização deste controle. Todavia, os referidos julgados vão além e estabelecem que os referidos julgadores devem realizar o controle de convencionalidade de ofício.

Primeiramente, é possível verificar que a Corte Interamericana de Direitos Humanos, no ano de 2006, no julgamento do caso denominado de Almonacid Arellano e outros vs. Chile, proferiu, pela primeira vez, seu entendimento, no item 124, no sentido de que o "Poder Judiciário deve exercer uma espécie de 'controle de convencionalidade' entre as normas jurídicas internas aplicadas a casos concretos e a Convenção Americana sobre Direitos Humanos" (I/A COURT H.R., 2006a), aduzindo que no momento em que Estado ratifica determinado tratado internacional como a Convenção Americana, os Juízes internos, também estão submetidos ao diploma normativo, o que traz a obrigação de velar para que os efeitos das disposições da Convenção não sejam diminuídos por força de leis que dispõem de forma contrária, levando-se em consideração não somente as disposições do tratado, mas, também, a interpretação que a Corte tem evidenciado em sua jurisprudência.

No âmbito dos Casos La Cantuta Vs. Peru (I/A COURT H.R., 2006b), Boyce Vs. Barbados (I/A COURT H.R., 2007), Heliodoro-Portugal Vs. Panamá (I/A COURT H.R., 2008b) e Manuel Cepeda Vs. Colômbia (I/A COURT H.R., 2010c) a Corte Ratifica seu entendimento, referenciando a decisão do Caso Almonacid Arellano Vs. Chile (I/A COURT H.R., 2006a), explanada acima.

Com relação ao controle de convencionalidade difuso de ofício, a Corte Interamericana de Direitos Humanos, no mesmo ano, no item 128 do Case of the Dismissed Congressional Employees (Aguado-Alfaro) v. Peru (I/A COURT H.R., 2006c), enunciou, taxativamente, que "los órganos del Poder Judicial deben ejercer no sólo un control de constitucionalidad, sino también "de convencionalidad" ex 
officio entre las normas internas y la Convención Americana", evidenciando as obrigações dos Estados signatários em realizer o controle, pelo Poder Judiciário ex officio. O julgamento do Caso Fermín Ramírez y Raxcacó Reyes vs. Guatemala estabelece, novamente, o dever Estatal em exercer o controle de convencionalidade de ofício (I/A COURT H.R., 2008a).

Os julgados da Corte Interamericana continuaram a ratificar o referido entendimento no item 225 decisão do caso Cabrera García e Montiel-Flores v. México (I/A Court H.R., 2010a) e, nos mesmos termos, a Corte trouxe o seu entendimento no item 193 da decisão do caso Gelman vs. Uruguai, salientando que os "juízes e órgãos vinculados à administração de justiça, em todos os níveis, possuem a obrigação de exercer ex officio um "controle de convencionalidade" entre as normas internas e a Convenção Americana." (I/A COURT H.R., 2011).

No caso Gomes Lund vs. Brasil, é possível verificar, novamente, no item 176 do julgamento, a ordem expressa de que "o Poder Judiciário, nesse sentido, está internacionalmente obrigado a exercer um 'controle de convencionalidade' ex officio entre as normas internas e a Convenção Americana", estabelecendo, diretamente, com relação ao Estado brasileiro, que o Poder Judiciário deve realizer, por meio de qualquer Juízo singular ou Tribunal, o controle de convencionalidade difuso de ofício. Saliente-se que o julgamento deste caso concluiu que o Estado brasileiro "descumpriu a obrigação de adequar seu direito interno à Convenção Americana sobre Direitos Humanos, contida em seu artigo 2, em relação aos artigos 8.1, 25 e 1.1 do mesmo instrumento.” (I/A COURT H.R., 2010b). O Julgamento ainda evidenciou que o Estado brasileiro foi responsável pela violação de diversos direitos humanos fundamentais previstos da Convenção Americana de Direitos Humanos, condenando o Brasil, nos seus pontos resolutivos, a pagar quantias à título de indenizações e adotar uma série de medidas a fim de evitar casos semelhantes.

No mesmo sentido estabelece Lucchetti (2008, p. 108) ao aduzir que "el Estado tiene el deber de iniciar ex officio y sin dilación, una investigación seria, imparcial y efectiva." Midón (2016, p. 102), por sua vez, assevera que "la Corte IDH estableció con toda precision que el deber de los tribunales para realizer la faena de contralor era atributo que debía ejercerse de oficio." Por fim, Lértora (2016, p. 254) estabelece que "en la function jurisdiccional, el control de convencionalidad debe ser efectuado de oficio por parte de los Magistrados [...]"

Vislumbra-se, deste modo, que o controle de convencionalidade, em sua modalidade difusa pode, e deve, ser aplicado por todo juiz singular ou tribunal, ex officio, com o objetivo de que seja realizada a adequação das normativas infraconstitucionais brasileiras ao que dispõe os tratados internacionais que versam sobre direitos humanos. Vale salientar que, como os tratados internacionais de direitos humanos, quando incorporados em conformidade com o disposto no $\$$ $3^{\circ}$ do artigo $5^{\circ}$ da Constituição, não são iguais, mas, equivalentes às emendas constitucionais, não deve ser aplicada a cláusula de reserva de plenário, prevista no artigo 97 da Constituição, no âmbito da declaração de inconvencionalidade difusa realizada pelos Tribunais. Percebe-se este fator uma vez 
que o artigo 97 da Constituição é claro ao se referir apenas à declaração de inconstitucionalidade, não exigindo, entretanto com relação ao controle que tem como parâmetro os tratados internacionais.

Ademais, Mazzuoli (2015, p. 244-245) explicita que o Poder Judiciário dos Estados-Partes da Convenção deve, de forma obrigatória, aplicar, de ofício, o controle de convencionalidade na sua modalidade difusa. Aduz o autor que se determinado Estado se recusar a aplicar o mecanismo ex officio, já estaria constituído motivo suficiente para acarretar a responsabilidade internacional do Estado por ter este violado os Direitos Humanos.

Neste sentido, saliente-se a importância do artigo $2^{\circ}$ da Convenção Americana de Direitos Humanos, onde foi definido que os Estados Partes se comprometeram a adotar as medidas legislativas ou de outra natureza que forem necessárias para efetivação dos direitos e liberdades previstos na convenção, inclusive em se tratando da jurisdição estatal. Ademais, a Convenção de Viena Sobre o Direito dos Tratados, promulgada pelo Decreto n. 7.030, de 14 de dezembro de 2009, em seu artigo 27, é claro ao estabelecer que "Uma parte não pode invocar as disposições de seu direito interno para justificar o inadimplemento de um tratado. Esta regra não prejudica o artigo 46." (BRASIL, 2009).

Conclui-se, desta forma, que é um dever dos Julgadores a realização do controle de convencionalidade na sua modalidade difusa de ofício. Entretanto, deve-se verificar a aplicação processual do referido controle, sendo este utilizado de acordo com as normativas processuais constitucionais, ou seja, sendo aplicado da melhor forma possível no que tange às partes litigantes.

Para tanto, deve ser verificado o controle de convencionalidade em sua modalidade difusa, à luz dos princípios do devido processo legal, do contraditório e da ampla defesa, bem como das normativas constitucionais e do Código de Processo Civil de 2015, verificando-se, neste sentido, a correta forma de proferir determinada decisão que controle a convencionalidade das leis, bem como de determinados atos normativos.

\section{0 controle de convencionalidade de ofício e a vedação das decisões surpresa}

É evidente o caráter fundamental da utilização do mecanismo do controle de convencionalidade no ordenamento jurídico brasileiro. A partir deste, é possível controlar o ordenamento, adequando a legislação, bem como determinados atos administrativos ao que está previsto nos tratados internacionais que versam sobre direitos humanos.

O referido controle ainda se mostra mais efetivo e próximo aos jurisdicionados, à medida que seja procedida na modalidade difusa, uma vez que, sendo o controle de convencionalidade utilizado de maneira incidental em determinado caso concreto, qualquer Juiz ou Tribunal possuirá o dever de realizá-lo, sob pena de deixar de garantir os direitos humanos fundamentais, podendo ser até responsabilizado o Estado, como já discutido alhures.

Vislumbra-se, ademais, que o julgador tem não só o dever de realizar o controle de convencionalidade difuso por força da provocação no que se refere às partes, mas possui também o 
dever fazê-lo de ofício, como já demonstrado pela farta jurisprudência da Corte Interamericana de Direitos Humanos.

Entretanto, é certo que esse controle deve seguir as normativas do direito processual civil. Neste sentido, devem ser observados os já enunciados princípios do devido processo legal, do contraditório, bem como da ampla defesa. Em que pese sejam princípios constitucionais, o Código de Processo Civil de 2015 ratifica e reafirma a importância do contraditório e da ampla defesa no que se refere ao direito processual civil brasileiro, ao afirmar, no seu artigo $7^{\circ}$, que "É assegurada às partes paridade de tratamento em relação ao exercício de direitos e faculdades processuais, aos meios de defesa, aos ônus, aos deveres e à aplicação de sanções processuais, competindo ao juiz zelar pelo efetivo contraditório." (BRASIL, 2015).

Neste sentido, verifica-se que a lei tem o intuito claro de promover um processo isonômico, fundamentado na paridade de armas, no contraditório, bem como no devido processo legal, diante do disposto no artigo 10 do mesmo diploma processual que estabelece que "O juiz não pode decidir, em grau algum de jurisdição, com base em fundamento a respeito do qual não se tenha dado às partes oportunidade de se manifestar, ainda que se trate de matéria sobre a qual deva decidir de ofício." (BRASIL, 2015).

Este dispositivo consagra a vedação das chamadas "decisões surpresa" ao definir que, mesmo no que tange às decisões tomadas de ofício, o julgador deve, de forma obrigatória, oferecer oportunidade de manifestação às partes. Verifica-se, portanto, que todo o trâmite processual deve estar pautado na ampla defesa, valorizando o contraditório e o devido processo legal.

Existem diversos precedentes acerca da importância da vedação desse tipo de decisão no processo civil brasileiro, que decretam a nulidade da decisão que desrespeita tal mandamento. Entre estes, vale destacar: TJSP. AI n. 2025237-12.2017.8.26.0000; TJSP. APL SP 1045654-89.2015.8.26.0576; TJSP. APL SP 0125943-09.2009.8.26.0100; TJDF. APL DF 0004194-81.2008.807.0005; TJRS APL 70040791626.

Ocorre que, o Superior Tribunal de Justiça, em recente julgado (Edcl no REsp 1.280.825), não acolheu embargos declaratórios, entendendo que não se aplica o princípio da vedação das decisões surpresa, em virtude de a decisão ter adotado fundamentação legal diferente da apresentadas pelas partes, explicitando que "Os fatos da causa devem ser submetidos ao contraditório, não o ordenamento jurídico, o qual é de conhecimento presumido não só do juiz (iura novit curia), mas de todos os sujeitos ao império da lei, conforme presunção jure et de jure." (BRASIL, 1942).

Verifica-se, deste modo, que para cumprir o Código de Processo Civil Brasileiro, bem como as normativas principiológicas constitucionais processuais, os Tribunais de Justiça têm entendido que ao proferir qualquer decisão, mesmo as mais simples, deve-se oferecer às partes oportunidade de manifestação. Ocorre que o Superior Tribunal de Justiça não coadunou com isso, o que é uma posição questionável. 
Entende-se, entretanto, que o não cumprimento da referida norma macula a decisão de vício que impõe a nulidade absoluta ao ato. Portanto, verifica-se que o controle de convencionalidade (ou de supralegalidade) difuso ex officio deve ser aplicado de forma a respeitar a vedação das ditas "decisões surpresa". Desta forma, ao se utilizar o mecanismo do controle de convencionalidade incidental, deve o julgador, independentemente do grau de jurisdição, ao formar seu livre convencimento no que se refere à necessidade de proceder com o controle de determinada norma, oferecer às partes oportunidade de manifestação.

Verifica-se que, oferecendo-se às partes oportunidade de manifestação, o magistrado estará contribuindo para a efetivação do devido processo legal, tanto no seu aspecto formal quanto no aspecto material. Impõe-se registrar que, proferindo o julgador uma decisão sem respeitar o contraditório e o devido processo legal, declarando a inconvencionalidade de determinada norma, esta deve ser declarada nula, uma vez que não foram observados dispositivos legais e constitucionais.

\section{Conclusão}

Diante do quanto abordado na presente pesquisa, é possível concluir que o controle de convencionalidade é um indispensável mecanismo a ser aplicado na jurisdição nacional, uma vez as convenções internacionais das quais o Brasil é signatário integrarem o ordenamento jurídico brasileiro. É mister promover a adequação das leis e atos normativos ao disposto nos tratados internacionais que versem sobre direitos humanos, sobretudo. Trata-se de integração normativa imprescindível. Pôde-se concluir, ademais, que com esse controle, os direitos humanos fundamentais passam a ter maior efetividade, como resta demonstrado no âmbito da Corte Interamericana de Direitos, bem como na grande maioria dos ordenamentos jurídicos dos Estados latino-americanos.

Ademais, conclui-se que o mecanismo de controle pesquisado deve ser aplicado na sua modalidade difusa, no âmbito incidental e concreto, produzindo efeitos inter partes no que se refere às partes processuais. A jurisprudência da Corte Interamericana de Direitos Humanos é clara ao estabelecer que o controle de convencionalidade deve ser aplicado na modalidade difusa, devendo o poder judiciário, por meio dos seus juízes singulares ou tribunais, aplicar, de forma obrigatória, o referido mecanismo de controle. Como investigado, a partir do entendimento do Supremo Tribunal Federal, deverá ser aplicado o controle de supralegalidade, tendo como parâmetro os tratados internacionais de direitos humanos incorporados que não foram submetidos ao procedimento previsto no artigo $5^{\circ}$, $₫ 3^{\circ}$ da Constituição Federal.

Vislumbra-se, ademais, que a Corte Interamericana foi mais além do que determinar a obrigatória realização do controle de convencionalidade na sua modalidade difusa, pelos julgadores, ao estabelecer que esta modalidade deve ser aplicada de ofício, sempre que possível, no bojo do processo. 
Neste sentido, é cediço que o processo civil brasileiro é regulamentado por normativas constitucionais que estabelecem os princípios do devido processo legal, do contraditório, bem como da ampla defesa. Ademais, a partir da promulgação do Código de Processo Civil de 2015, os princípios processuais foram ratificados também no âmbito legislativo, tendo sido prevista, ainda, a vedação das "decisões surpresa", pela redação do artigo 10, mesmo quando a decisão em questão seja proferida de ofício.

Conclui-se, deste modo, que o mecanismo do controle de convencionalidade deve ser aplicado de forma incidental e concreta, ou seja, na modalidade difusa, de ofício, obrigatoriamente, por todo juiz singular ou tribunal. Entretanto, para isso, o julgador deve respeitar as normativas processuais estabelecidas, notadamente no que se refere ao princípio constitucional do devido processo legal, devendo oferecer às partes processuais oportunidade de manifestação sobre aquilo que foi considerado contrário à convenção, ou seja sobre a matéria específica do controle de convencionalidade realizado, evitando, deste modo, qualquer decisão surpresa no âmbito do processo, bem como a posterior decretação de nulidade da referida decisão.

\section{Referências}

ABBOUD, Georges. Controle de convencionalidade e direitos fundamentais. 2017. Disponível em: https://www.academia.edu/33795570/Controle_de_convencionalidade_e_direitos_fundamentais. Acesso em: 23 mar. 2018.

ALCALÁ, Humberto Nogueira. Los Desafios del Control de Convencionalidad del Corpus Iuris Interamericano para los Tribunales Nacionales, y su Diferenciación con el Control de Constitucionalidad. Controle de Convencionalidade: um panorama latino-americano: Brasil, Argentina, Chile, México, Peru, Uruguai. Brasília, DF: Gazeta Jurídica, 2013.

BELAUNDE, Domingo Garcia; MANCHEGO, José Felix Palomino. El Control de Convencionalidad en el Perú. Controle de Convencionalidade: um panorama latino-americano: Brasil, Argentina, Chile, México, Peru, Uruguai. Brasília, DF: Gazeta Jurídica, 2013.

BRASIL. Constituição: República Federativa do Brasil de 1988. Brasília, DF: Senado Federal, 1988.

BRASIL. Decreto-Lei n. 4.657, de 4 de setembro de 1942. Lei de Introdução às normas do Direito Brasileiro. Diário Oficial da União, Brasília, DF, 9 set. 1942. Disponível em: http://www.planalto. gov.br/ccivil_03/decreto-lei/Del4657compilado.htm. Acesso em: 17 ago. 2018.

BRASIL. Decreto n. 7.030, de 14 de dezembro de 2009. Promulga a Convenção de Viena sobre o Direito dos Tratados, concluída em 23 de maio de 1969, com reserva aos Artigos 25 e 66. Diário Oficial da União, Brasília, DF, 15 dez. 2009. Disponível em: http://www.planalto.gov.br/ccivil_03/_ ato2007-2010/2009/decreto/d7030.htm. Acesso em: 15 ago. 2018.

BRASIL. Lei n. 13.105, de 16 de março de 2015. Código de Processo Civil. Diário Oficial da União, Brasília, DF, 17 mar. 2015. Disponível em: http://www.planalto.gov.br/ccivil_03/_ato20152018/2015/lei/113105.htm. Acesso em: 23 mar. 2018. 
CANOTILHO, José Joaquim Gomes. Direito Constitucional e Teoria da Constituição. 7. ed. Coimbra: Almedina, 2003.

CUNHA JÚNIOR, Dirley da. A Natureza Material Dos Direitos Fundamentais. 2015. Disponível em: https://www.brasiljuridico.com.br/artigos/a-natureza-material-dos-direitos-fundamentais.-por-dirley-da-cunha-junior. Acesso em: 23 mar. 2018.

CUNHA JÚNIOR, Dirley da. Entrevista concedida a Matheus Lins Rocha, 31 ago. 2016.

FIGUEIREDO, Marcelo. O controle de constitucionalidade e de convencionalidade no Brasil. São Paulo: Malheiros, 2016.

GALLICCHIO, Eduardo G. Esteva. El Control de Convencionalidad en Uruguay. Controle de Convencionalidade: um panorama latino-americano: Brasil, Argentina, Chile, México, Peru, Uruguai. Brasília, DF: Gazeta Jurídica, 2013.

GUERRA, Sidney. O Sistema Interamericano de Proteção dos Direitos Humanos e o Controle de Convencionalidade. São Paulo: Atlas, 2013.

I/A COURT H.R. Caso Gelman Vs. Uruguai. Sentença 24 fev. 2011.

I/A COURT H.R. Case of Almonacid Arellano v. Chile. Preliminary Objections, Merits, Reparations and Costs. Series C n. 154. Judgment of September 26, 2006a. Disponível em: http://www.corteidh.or.cr/cf/Jurisprudencia2/index.cfm?lang=en. Acesso em: 15 mar. 2018.

I/A COURT H.R. Case of Boyce v. Barbados. Preliminary Objection, Merits, Reparations and Costs. Series C n. 169. Judgment of November 20, 2007. Disponível em: http://www.corteidh.or.cr/docs/ casos/articulos/seriec_169_esp.pdf. Acesso em: 4 ago. 2018.

I/A COURT H.R. Case of Cabrera García and Montiel-Flores v. Mexico. Preliminary Objection, Merits, Reparations, and Costs. Series C n. 220. Judgment of November 26, 2010a. Disponível em: http://www.corteidh.or.cr/docs/casos/articulos/seriec_220_esp.pdf. Acesso em: 22 mar. 2018.

I/A COURT H.R. Case of Fermin Ramírez v. Guatemala. Monitoring Compliance with Judgment. Order of the Inter-American Court of Human Rights of May 09, 2008a. Disponível em: http://corteidh.or.cr/docs/supervisiones/Fermin_09_05_08.pdf. Acesso em: 4 ago. 2018.

I/A COURT H.R. Case of Gomes Lund. ("Guerrilha do Araguaia") v. Brazil. Preliminary Objections, Merits, Reparations, and Costs. Series C n. 219. Judgment of November 24, 2010b. Disponível em: http://www.corteidh.or.cr/cf/Jurisprudencia2/index.cfm?lang=en. Acesso em: 4 ago. 2018.

I/A COURT H.R. Case of Heliodoro-Portugal v. Panamá. Preliminary Objections, Merits, Reparations, and Costs. Series C n. 186. Judgment of August 12, 2008b. Disponível em: http://www.corteidh. or.cr/docs/casos/articulos/seriec_186_esp.pdf. Acesso em: 4 ago. 2018.

I/A COURT H.R. Case of La Cantuta v. Peru. Merits, Reparations and Costs. Series C n. 162. Judgment of November 29, 2006 b.

I/A COURT H.R. Case of Manuel Cepeda Vargas v. Colombia. Preliminary Objections, Merits, Reparations and Costs. Series C n. 213. Judgment of May 26, 2010c. Disponível em: http://www.corteidh.or.cr/docs/casos/articulos/seriec_213_esp.pdf. Acesso em: Acesso em: 4 ago. 2018. 
I/A COURT H.R. Case of Myrna Mack Chang v. Guatemala. Merits, Reparations and Costs. Series C n. 101. Judgment of November 25, 2003.

I/A COURT H.R. Case of the Dismissed Congressional Employees (Aguado-Alfaro) v. Peru. Preliminary Objections, Merits, Reparations and Costs. Series C n. 158. Judgment of November 24, 2006 c.

Disponível em: http://www.corteidh.or.cr/cf/Jurisprudencia2/index.cfm?lang=en. Acesso em: 18 mar. 2018.

LÉRTORA, Martha Helia Altabe de. Control judicial de convencionalidad de oficio. In: MANILI, Pablo Luis et al. Derechos humanos y control de convencionalidad. Chaco, Argentina: Contexto Libros, 2016.

LUCCHETTI, Alberto J. Los Jueces y algunos caminhos del control de convencionalidad. El control de convencionalidad. Buenos Aires: Edia, 2008.

MAC-GREGOR, Eduardo Ferrer. Interpretación Conforme y Control Difuso de Convencionalidad el Nuevo Paradigma Para el Juez Mexicano. Controle de Convencionalidade: um panorama latino-americano: Brasil, Argentina, Chile, México, Peru, Uruguai. Brasília, DF: Gazeta Jurídica, 2013.

MAZZUOLI, Valério de Oliveira. Curso de direitos humanos. 2. ed. São Paulo: Método, 2015.

MAZZUOLI, Valério de Oliveira. O controle jurisdicional de convencionalidade das leis. 3. ed. São Paulo: Revista dos Tribunais, 2013.

MELLO, Celso de Albuquerque. Curso de Direito Internacional Público. 11. ed. Rio de Janeiro: Renovar, 1997.

MELLO, Celso de Albuquerque. $\bigcirc 2^{\circ}$ do art. $5^{\circ}$ da Constituição Federal. In: TORRES, Ricardo Lobo (org.). Teoria dos Direitos Fundamentais. 2. ed. Rio de Janeiro: Renovar, 2001.

MIDÓN, Mario A. R. Control de Convencionalidad. Ciudad Autónoma de Buenos Aires: Astrea, 2016.

PIOVESAN, Flávia. Direitos humanos e o Direito Constitucional Internacional. São Paulo: Max Limonad, 1996.

PIZZOLO, Calogero. Control de Convencionalidad y su Recepción por la Corte Suprema de Justicia en Argentina. Controle de Convencionalidade: um panorama latino-americano: Brasil, Argentina, Chile, México, Peru, Uruguai. Brasília, DF: Gazeta Jurídica, 2013.

SAGÜÉS, Néstor Pedro. El Control de Convencionalidad en Argentina. Controle de Convencionalidade: um panorama latino-americano: Brasil, Argentina, Chile, México, Peru, Uruguai. Brasília, DF: Gazeta Jurídica, 2013.

SUPREMA CORTE DE JUSTICIA DE LA NACIÓN DEL MÉXICO. Ação Direta de Inconstitucionalidade 5.240, 20 de agosto de 2015. Ministro: Teori Zavascki. Disponível em: http://redir.stf.jus.br/ paginadorpub/paginador.jsp?docTP=TP\&docID=10167333. Acesso em: 15 mar. 2018.

SUPREMA CORTE DE JUSTICIA DE LA NACIÓN DEL MÉXICO. Contenido de la versión taquigráfica de la sesión pública ordinaria del pleno de La Suprema Corte de Justicia de la Nación, celebrada el Martes 12 de Julio de 2011. p. 11. Disponível em: https://www.scjn.gob.mx/PLENO/ ver_taquigraficas/12072011PO13SN.pdf. Acesso em: 22 out. 2016. 
SUPREMA CORTE DE JUSTICIA DE LA NACIÓN DEL MÉXICO. Voto Vogal do Acórdão do Recurso Extraordinário 466.343-SP. Ministro: Cezar Peluso. 3 dez. 2008. Disponível em: http://www.stf.jus. br/imprensa/pdf/re466343.pdf. Acesso em: 15 mar. 2018.

TRIBUNAL CONSTITUCIONAL CHILENO. Sentença Rol 1361-09. Relatora: Sandra Ponce de León Salucci. 7 abr. 2009.

TRIBUNAL CONSTITUCIONAL DO ESTADO DO PERU. Exp.n. 01458-2007-PA/TC. 2007. Disponível em: http://www.tc.gob.pe/jurisprudencia/2008/01458-2007-AA.html. Acesso em: 4 ago. 2018.

TRIBUNAL SUPERIOR DO TRABALHO. (7. Turma). Processo: RR - 1072-72.2011.5.02.0384. Relator: Ministro Cláudio Mascarenhas Brandão. Julgamento em 24 de setembro de 2014. DEJT, 3 out. 2014. Disponível em: http://www.tst.jus.br/consulta-unificada. Acesso em: 12 ago. 2018.

TRINDADE, Antônio Augusto Cançado. A proteção internacional dos direitos humanos: fundamentos jurídicos e instrumentos básicos. São Paulo: Saraiva, 1991. 
